\title{
Papillary fibroelastoma in tricuspid valve: An unusual cause of atypical chest pain
}

\author{
Kyung Hwa Kim, MD, PhD, and Jong Bum Choi, MD, PhD
}

A 72-year-old woman had occasional atypical chest pain, which had been worsening the previous 6 months. The electrocardiogram was negative for ischemia and chronic myocardial infarction. Cardiac enzymes were essentially within normal limits. Transthoracic echocardiography showed a highly mobile right atrial mass with a finding compatible with a myxoma (Figure 1) and revealed the mass creating a tricuspid stenosis (maximum pressure gradient, 25 $\mathrm{mm} \mathrm{Hg}$ ). It was prolapsing in and out of the right ventricle with movement of the valve (Figure 1). Coronary angiogram revealed no coronary artery disease.

At surgery, the mass resembled a sea anemone, and a $2.2 \times$ $2.1 \mathrm{~cm}$ mass arising from the septal leaflet of the tricuspid valve near the commissure between the septal and the posterior leaflets (Figure 2) was excised. The defect in the septal leaflet was repaired primarily with 5-0 polypropylene simple suture. Inasmuch as the tricuspid valve appeared to be dilated, DeVega suture annuloplasty was performed.

The microscopic sections provided the diagnosis of papillary fibroelastoma. Grossly, the mass resembled a sea anemone and was composed of many multiple papillary fronds (Figure 3, A). Histologic examination demonstrated papillary fronds with central hypocellular, hyalinized stroma covered by a single layer of endothelial cells (Figure 3,B). The postoperative course was uneventful and after 3 months of follow-up, she remains free of symptoms.

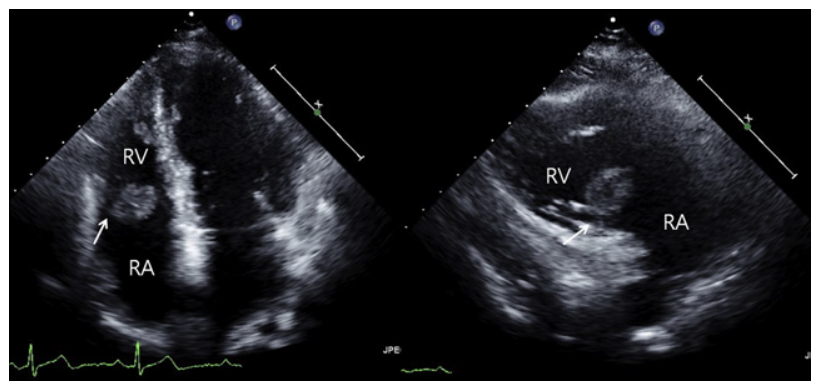

FIGURE 1. Transthoracic echocardiography showing a highly mobile right atrial mass with a finding compatible with a myxoma plus a mass creating tricuspid stenosis. $R V$, Right ventricle; $R A$, right atrium.

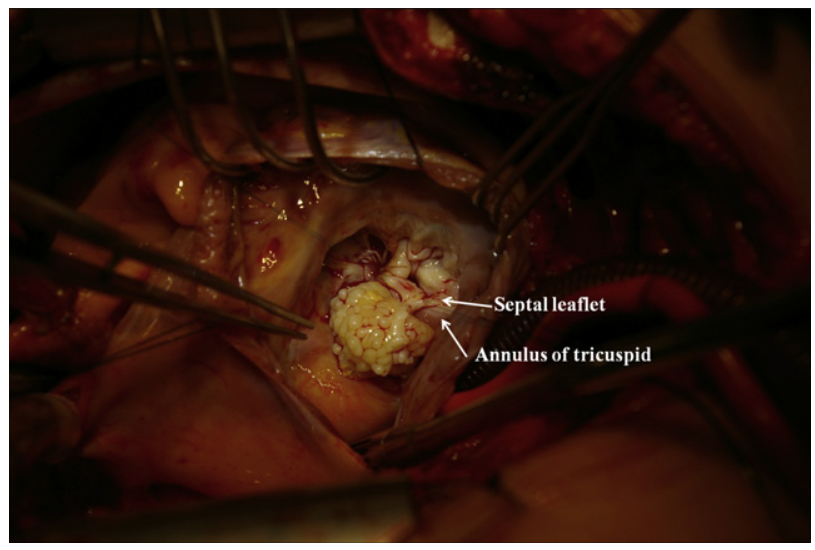

FIGURE 2. A $2.2 \times 2.1 \mathrm{~cm}$ mass arising from the septal leaflet of the tricuspid valve near the commissure between the septal and the posterior leaflets was excised.

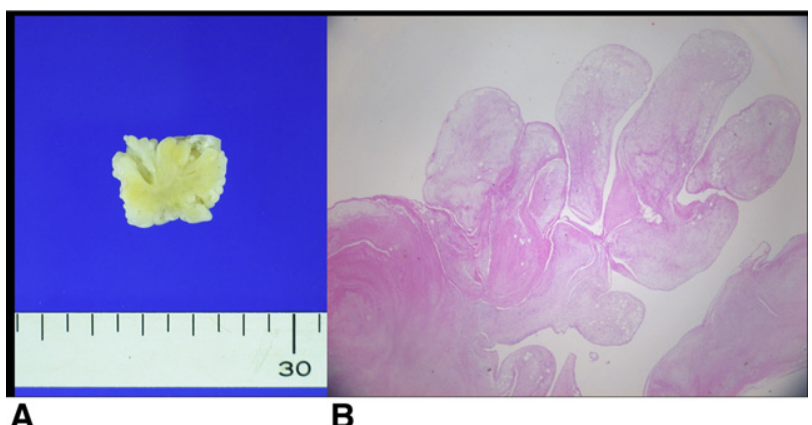

FIGURE 3. A, Grossly, the mass resembled a sea anemone and was composed of many multiple papillary fronds. B, Histologic examination demonstrated papillary fronds with central hypocellular, hyalinized stroma covered by a single layer of endothelial cells.
From the Department of Thoracic and Cardiovascular Surgery, Chonbuk National University Medical School, Jeonju, Republic of Korea.

Disclosures: Authors have nothing to disclose with regard to commercial support.

Received for publication Dec 14, 2012; accepted for publication Dec 20, 2012; available ahead of print Jan 18, 2013.

Address for reprints: Kyung Hwa Kim, MD, PhD, Department of Thoracic and Cardiovascular Surgery, Chonbuk National University Medical School, San 2-20, Geumam-dong, Deokjin-gu, Jeonju, 561-180, South Korea (E-mail: tcskimgh@ gmail.com).

J Thorac Cardiovasc Surg 2013;145:1131

$0022-5223 / \$ 36.00$

Copyright (c) 2013 by The American Association for Thoracic Surgery

http://dx.doi.org/10.1016/j.jtcvs.2012.12.076 